\title{
MULHERES DO PETRÓLEO: SENTIDOS ATRIBUÍDOS POR HOMENS E MULHERES A TAREFAS TRADICIONALMENTE CONSIDERADAS MASCULINAS
}

\author{
Petroleum Women: Attributed Senses For Men And \\ Women On Works Traditionally \\ Considered Males
}

\author{
Marly Terezinha Perrelli ${ }^{1}$ \\ Maria Juracy Filgueiras Toneli ${ }^{2}$
}

\section{Resumo}

Este artigo é oriundo da pesquisa de mestrado, que permite apreciar o mundo do trabalho das mulheres que exercem o cargo de operadoras na Petrobrás, anteriormente exclusivo do domínio masculino. A intenção da pesquisa foi a de analisar as relações interpessoais e intrapessoais com o trabalho sob a ótica de gênero. Os dados foram coletados por meio de entrevistas individuais, semi-estruturadas, submetidas à análise de conteúdo temática. Os resultados obtidos indicam o crescimento do número de mulheres inseridas em cargos tradicionalmente masculinos na Petrobrás. Demonstram que elementos como força física não determinam 0 ingresso das mulheres em tarefas antes não ocupadas por elas. Constata-se também o acréscimo de outra jornada de trabalho, pois, além do trabalho formal e daquele exercido no âmbito doméstico, dedicam-se a outras atividades profissionais como: a abertura de seu próprio negócio, atividades em outras empresas ou prestação de serviços gratuito na comunidade. É relevante destacaro papel facilitador da constituição de 1988 no processo de inclusão das mulheres no mundo do trabalho apontando a necessidade de se promover esforços na construção de igualdades de gênero. Sendo característica predominante das mulheres nessa década, a conquista da oportunidade de trabalho, os informantes destacaram como sendo fator determinante dessa condição a "competência".

Palavras-chave: Mulher e trabalho; Gênero; Ocupação feminina e trabalho feminino.

1 Mestre em Psicologia pela Universidade Federal de Santa Catarina - UFSC, professora do curso de graduação Psicologia da Universidade do Contestado - UnC, Núcleo Porto União. Endereço: R: Joaquim Ferreira Guimarães, 1191 - CEP $83900-000$ - São Mateus do Sul - PR. E-mail: marlyperrelli2002@yahoo.com.br.

2 Doutora em Psicologia, professora do curso de Pós-graduação mestrado e doutorado da Universidade Federal de Santa Catarina - UFSC. 


\section{Abstract}

This article is originating from of research that allows appreciating the world of the women's work that you/ they exercise the position of operators in Petrobrás, previously exclusive of the masculine domain. The intention of the research was the one of analyzing the relationships interpesonas and intrapersonas with the work under the gender optics. The data were collected through individual interviews, semi-structured, submitted to the thematic content analysis. The obtained results indicate the growth of the number of women inserted in positions traditionally masculine in Petrobrás. They demonstrate that elements as physical force doesn't determine the women's entrance before in tasks no busy for them. It is also verified the increment of another work day, because, besides the formal work and of that exercised in the domestic extent, they are devoted to other professional activities as: the opening of his/her own business, activities in other companies or free services rendered in the community. It is relevant to detach the facilitative paper of the constitution of 1988 in the process of the women's inclusion in the world of the work pointing the need to promote efforts in the construction of gender equalities. Being characteristic predominant of the women on that decade, the conquest of the work opportunity, the informers highlighted how decisive factor of that condition, the "competence" being.

Keywords: Woman and work; Gender; Feminine occupation and feminine work.

\section{Introdução}

Qual é o espaço que as mulheres ocupam no mundo do trabalho? Como modificou o mundo "cor de rosa" no qual a delicadeza da mulher estava acima de qualquer igualdade? A "rainha do lar" perdurou nas homenagens às mulheres. Hoje, de que cenário estamos falando? Homens e mulheres executando as mesmas tarefas: é uma realidade possível? Em que bases e com quais características? Estas perguntas permearam a trajetória dessa pesquisa construindo suas respostas no cenário das mulheres na esfera do trabalho.

Na busca de dados para consolidar a relevância dessa pesquisa, investigou-se inicialmente nos bancos de dados do IBGE (Instituto Brasileiro de Geografia e Estatística). Do total de 48,2 milhões de famílias existentes no país, $26,7 \%$ estão sob a responsabilidade de uma mulher, o que corresponde a 12,8 milhões de famílias. No censo de 1991, elas eram responsáveis por 7,7 milhões de famílias, ou $20,5 \%$ do total de 37,5 milhões. 0 crescimento deste tipo de família pode ser explicado por dois fatores principais: a elevada esperança de vida da mulher, aproximadamente oito anos mais alta que a do homem, e a maior autonomia econômica adquirida nas últimas duas décadas (PNAD/IBGE/2000), visualizando assim o crescimento quantitativo e progressivo das mulheres em ocupações formais de trabalho.
Devemos destacar a consulta realizada na Síntese de Indicadores Sociais 2002, lançada pelo IBGE, que mostra que o traço mais marcante da sociedade brasileira é a desigualdade. Na desigualdade por gênero, as mulheres ganham menos que os homens em todos os estados brasileiros e em todos os níveis de escolaridade. A trajetória das mulheres, segundo as variáveis demográficas, é marcada por uma crescente participação no mundo do trabalho e pela permanência de uma marcante desigualdade entre homens e mulheres em cargos $^{3}$ e tarefas ${ }^{4}$ executadas nas organizações, bem como entre salários percebidos no exercício da mesma função (PNAD, 1999; Censo, 2002).

Segundo Perrot (1998), em tempos de guerra na Europa, os homens estavam na frente de batalha e as mulheres na retaguarda. Executavam tarefas tradicionalmente masculinas e, com isso, invadiram espaços que antes não ocupavam.

Essas representações atravessam o tempo e assumem várias formas conforme a época, desenhando quadro a quadro dos acontecimentos da história. Ao contrário do que diz o senso comum, as mulheres sempre trabalharam, e muito. As tarefas indispensáveis do trabalho doméstico diariamente eram e são executadas por milhares de mulheres, as quais contribuem para a sobrevivência da família, pois realizando as tarefas domiciliares, de uma certa maneira constitui a força de trabalho, mas sem remuneração, afirmam Bruschi-

\footnotetext{
${ }^{3}$ Cargo, segundo Chiavenato (2000), são tarefas executadas de maneira cíclica ou repetitiva.

${ }^{4}$ Tarefa, segundo Chiavenato (2000), é toda atividade executada por uma pessoa em seu trabalho dentro da organização.
} 
ni \& Rosemberg (1982), em sua obra "Trabalhadoras do Brasil".

As mulheres então, progressivamente começam a superar as diversas representações pejorativas acerca do feminino, até então associado a características vistas como inferiores e com menos valor do que os atributos associados ao mundo masculino, por exemplo: o forte se sobrepõe ao frágil, o corajoso ao covarde, o alto ao baixo, o armojado ao tímido (Amaral, 1999). Outro exemplo clássico pode ser percebido em Fiúza (1997), que lembra a cor "rosa" como um símbolo socialmente reconhecido como pertencente ao gênero feminino.

Bruschini (1995) vem pesquisando a intensificação do crescimento da participação feminina no mercado de trabalho brasileiro, chamando atenção para a sua diversificação, sobretudo no espaço urbano. O marco desse crescimento mostra-se desde a década de 1970, quando os primeiros estudos sobre a mulher foram influenciados pelos movimentos feministas. Bruschini \& Rosemberg (1982) contribuem para a discussão e compressão sobre o trabalho da mulher, ao argumentarem que uma grande parte da população considerada "inativa" encontra-se efetivamente ocupada, ou seja, trabalhando na produção doméstica não remunerada e, entre os que trabalham, fica evidente que o conjunto da população das mulheres trabalhadoras cumpre diariamente uma dupla jornada de trabalho. As atividades domésticas não eram classificadas como atividades produtivas e, por este fato, deve-se ter cautela ao analisar os dados estatísticos relacionados ao número de trabalhadoras mulheres na esfera do mercado de trabalho, pois alguns desses dados não foram revelados pela desconsideração do trabalho doméstico.

A inserção das mulheres no sistema produtivo formal é fato historicamente comprovado. No entanto, se cresce a oportunidade, com ela cresce, também, a desigualdade. Para amenizar essas diferenças que se aceleram no decorrer do tempo, surge a necessidade de construir meios legais para frear o processo deficitário da disparidade no trabalho.

A Constituição de 1998 dispõe que "homens e mulheres sejam iguais perante a lei", essa lei possibilitou a abertura de espaço às mulheres nos concursos públicos para cargos que eram anteriormente destinados apenas aos homens. No caso da empresa pesquisada, a primeira mulher na história da Petrobrás a ocupar o cargo de operadora foi em 1989 ingressando por meio de concurso público. Mesmo com a oportunidade e acesso a esse cargo, as mulheres ainda são a minoria.

Também a OIT - Organização Internacional do Trabalho - em 2003 lançou o primeiro relatório global sobre discriminação no trabalho, contendo um panorama mundial. O relatório alerta que negligenciar ações que possam impedir "as crescentes desigualdades socioeconômicas" no mundo do trabalho podem ter efeitos desastrosos na coesão social nacional, estabilidade política e no crescimento econômico nos próximos anos.

Entre os avanços históricos das mulheres no mercado de trabalho é importante ressaltar as discussões em torno dos Estudos de Gênero que selam e edificam um processo que aprofundam a construção de novos estudos. Portanto, as relações de gênero nos espaços organizacionais contemporâneos possibilitam visualizar nesse grupo de mulheres pesquisadas, que elas buscam a oportunidade no trabalho, bem como se inserir em cargos nos quais o domínio era masculino. Esse ingresso das mulheres em organizações não se reduz a tentativas, contemplando participações efetivas de concursos abertos que determinam resultados reais do aumento das mulheres no mercado formal de trabalho. Esse aumento provoca modificações nas culturas empresariais, sustentadas na diversidade entre homens e mulheres compartilhando o mesmo espaço de trabalho.

No que se refere às relações de gênero no espaço organizacional, é importante destacar a utilização da palavra gênero desvincula-se da polaridade do masculino e feminino, e se encontra além das questões biológicas entre os sexos, sendo sim o estudo das relações humanas. Gênero é uma construção social que visa significar as relações de poder, de forma que "Masculinidade e feminilidade passariam a ser encaradas como posições de sujeito, não necessariamente restritas a machos ou fêmeas, biológicos" (Scott, 1995, p. 14).

Essa pesquisa fundamentou-se nos eixos teóricos de Joan Scott (2000): 1) As relações de gênero possuem uma dinâmica própria, mas também se articulam com outras formas e dominação e desigualdades sociais (raça, etnia, classe); 2) A perspectiva de gênero permite entender as relações sociais entre homens e mulheres, o que pressupõe mudanças e permanências, desconstruções, reconstruções de elementos simbólicos, práticas, 
comportamentos, normas, valores e representações; 3) A condição de gênero legitimada socialmente se constitui em imagens, referências pessoais que ocorre de maneira particular; 4) As relações de gênero, como as relações de poder, são marcadas por hierarquias, obediências e desigualdades, onde estão presentes os conflitos, tensões, negociações, alianças, sejam por meio da manutenção dos poderes masculinos, sejam na luta das mulheres a se desvincular desses domínios.

\section{Método}

Essa pesquisa foi desenvolvida em uma unidade da Petrobrás, localizada no sul do Brasil. Os instrumentos utilizados foram entrevistas individuais, semi-estruturadas. As entrevistas seguiram um roteiro preestabelecido a partir de indicadores obtidos por meio da revisão da literatura e da descrição de cargos. O roteiro foi submetido a um pré-teste com objetivo de verificar a eficácia do instrumento de coleta de informações.

Os sujeitos entrevistados foram quatro mulheres e quatro homens, entre as faixas etárias de 23 a 40 anos, sendo duas casadas com dois filhos, cada uma delas, com residências próprias e duas solteiras sem filhos, residindo com os pais. Em relação à escolaridade, todas elas têm o nível superior completo. Foram utilizados nomes fictícios para que os sujeitos da pesquisa não fossem identificados.

Para a escolha das mulheres a fazer parte dessa pesquisa, foi realizado um levantamento da quantidade de operadoras mulheres que trabalham na Petrobrás. Após esse mapeamento, buscou-se 0 contato com todas elas e a resposta foi positiva para a realização das entrevistas. O critério de escolha dos homens foi estarem dividindo espaços de trabalho com as mulheres no exercício do mesmo cargo na empresa. Essa estratégia de escolha teve como intenção a verificação da convivência entre pares, para que a pesquisa tivesse a oportunidade de obter a diversidade de opiniões dos sujeitos.

Foram utilizadas, como fontes de informações, os documentos e dados da biblioteca da empresa, diário de campo com as observações dos sujeitos no local das entrevistas e entrevistas obtidas por meio dos relatos verbais de homens e mulheres.

Informou-se aos sujeitos o teor da pesquisa, orientação sobre a ética e o sigilo das informações coletadas para que não se sentissem constran- gidos ao responderem as questões da entrevista e, a seguir, foi solicitado quem assinassem o Termo de Consentimento Livre e Esclarecido, bem como permissão para gravar seus discursos. No decorrer das entrevistas um fato marcante foi a preocupação manifestada pelas mulheres com o sigilo das informações que estavam formecendo. Várias vezes questionavam: "será que posso falar mesmo; o que você vai fazer com o que vou dizer agora; veja bem o que você vai fazer com essas informações; posso falar tudo?'. O fato de os participantes terem conhecimentos sobre o tema facilitou as respostas, pois repetiam e voltavam à pergunta de pesquisa, faziam localizações históricas, perguntavam sobre o tema e ressaltavam a importância da pesquisa, principalmente no casa das mulheres. As entrevistas com os homens procederam de maneira peculiar. Não havia as mesmas preocupações que as mulheres apresentaram sobre o sigilo das informações. Para eles, responder a perguntas sobre as mulheres em postos de trabalho é algo presente no avanço do desenvolvimento das competências com as mulheres.

Os locais da realização das entrevistas foram agendados pelos próprios sujeitos e ocorreram de forma diversificada. Algumas foram realizadas na empresa e outras na própria residência dos informantes, com datas e horários compatíveis e de acordo com a sua disponibilidade, com duração em média de uma hora e meia.

Os procedimentos de análise das informações para a organização da coleta das informações obtidas por meio das entrevistas basearam-se na análise dos discursos, que transpassa a linguagem enquanto sistema abstrato, mas considera os processos e as condições de produção da linguagem, pela análise da relação estabelecida pela fala dos sujeitos e a situação em que se produz, construindo assim sentido próprio, pessoal e único, a sua história (Orlandi, 2002).

A análise do discurso tem a finalidade de investigar os valores e as ideologias, entre outros aspectos. Os conteúdos foram analisados por meio de categorias sistemáticas, elaboradas a partir das falas dos homens e das mulheres que participaram da pesquisa, resgatando, assim, nos depoimentos dos informantes da pesquisa, informações sobre 0 espaço conquistado pelas mulheres na Petrobrás, os avanços em aspectos legais, com a Constituição de 1988, e também a sua trajetória e adaptação aos novos modelos organizacionais, tendo como participantes dessa interação as mulheres. 
A abordagem utilizada nessa pesquisa é a histórico-cultural correspondente à teoria de Vygotsky, com interfaces na análise dos discursos dos sujeitos.

\section{Resulta do e Discussão}

No Brasil é possível identificar algumas iniciativas inovadoras implementadas por empresas envolvidas em colocar em prática política de emprego, respeitando a diversidade no mundo do trabalho. Organizações como a Petrobrás, Banco do Brasil e Serpo efetivam ações de envolvimento social no que se refere à atualização da cultura empresarial, onde promovem a inserção das mulheres em tarefas tradicionalmente masculinas (Delgado, Cappellin, \& Soares, 2000). Entre essas empresas, a Petrobrás - Six tenta promover assim a eqüidade da oportunidade de emprego, tanto para homens como mulheres.

Para investigar a participação das mulheres no mercado de trabalho, Bruschini (1998) elegeu como indicadores das transformações demográficas, sociais, culturais, políticas e econômicas no Brasil os seguintes: a queda da taxa de fecundidade, o envelhecimento da população, o aumento do número de famílias chefiadas por mulheres, a expansão da escolaridade, os novos valores associados ao papel da mulher na sociedade brasileira e a redemocratização do país.

Em consonância com os indicadores que Bruschini elegeu, os sujeitos da pesquisa em seus discursos, identificaram-se os motivos pessoais e profissionais que os levaram a decidirem ingressar na Petrobrás. É importante ressaltar que esse ingresso ocorreu por meio de concurso público e, portanto, essa escolha emergiu da iniciativa do próprio sujeito de se submeter a esse processo seletivo para o cargo de operador.

A estabilidade financeira/salário ocupou lugar de destaque nos motivos pessoais nos depoimentos dos sujeitos da pesquisa. $\mathrm{O}$ fato de ser uma empresa conceituada foi unanimemente mencionado pelos sujeitos como motivo de ordem profissional que os levou a buscarem o ingresso na Petrobrás.

"O que queremos é oportunidade e não igualdade", esse discurso das mulheres permeou o imaginário social, sendo interpretado como competição com os homens em postos de trabalho onde as mulheres ainda não participaram. Delgado et al. (2000) apresentam um balanço do cenário internacional a respeito da desigualdade de oportunidades no trabalho e das estratégias que objetivam corrigi-la, denominadas ações afirmativas. Essas políticas têm como meta corrigir antigas e novas discriminações entre pares no mundo do trabalho, e colocar em ação atores sociais distintos, como os movimentos das mulheres, as organizações sindicais e as instituições do poder público, convergindo em modelar os primeiros princípios de igualdade entre homens e mulheres no corpo jurídico/legal e no cotidiano das relações democráticas.

Nos discursos obtidos, mulheres e homens traçam reflexões similares em relação à participação em tarefas tradicionalmente masculinas e relatam a igualdade de desempenho. Nadia afirma que as mulheres executam tarefas de forma igualitária: Não há nada que as mulheres não consigam fazer que eles também não consigam [Nadia]. As próprias mulheres perceberam as modificações no que se refere à sua autonomia na execução de atividades no trabalho, vivenciando assim o processo da igualdade, sem diferenciação pelo fato de ser homem ou mulher. A conquista do espaço de trabalho das mulheres em locais considerados de domínio masculino é o que destaca Murilo: Hoje eu acho que ela criou o espaço den tro do grupo, ao meu ver ela está de parabéns [Murilo].

Ao serem abordados a respeito das facilidades e dificuldades no desempenho de suas tarefas, os entrevistados explicitaram uma diversidade de opiniões. Atribuem inicialmente as facilidades em desempenhar suas tarefas à participação nos treinamentos, considerando fundamental o curso preparatório (no período do curso preparatório são considerados bolsistas até o seu término) para operadores, acontecendo nos seis primeiros meses que antecedem a entrada oficial na Petrobrás. Além disso, após ingressarem na empresa, passam constantemente por outros treinamentos relativos à área de segurança no trabalho, nos quais recebem orientações referentes aos procedimentos de atuação em situações emergenciais. Todos esses treinamentos possibilitam aprendizagens que levam à adaptação na empresa e à noção das tarefas a serem executadas, tornando, assim, o desempenho rotineiro e fácil e sem diferenciações específicas, o que ameniza as dificuldades que possam aparecer. 
As dificuldades mencionadas pelos homens em relação à atuação das mulheres no cargo de operadora foram: comunicação, esforço físico e entrosamento entre os componentes da equipe. Para as mulheres, as dificuldades encontram-se em memorizar termos técnicos e na inexperiência no trabalho.

Também poderíamos destacar que as dificuldades são suprimidas por meio de ações facilitadoras do trabalho das mulheres, como a cultura da empresa (valores) que viabiliza a oportunidade de trabalho e permite vivenciar as relações sociais no ambiente de trabalho de uma forma igualitária.

O avanço da inserção das mulheres na Petrobrás coincide com a pesquisa da Fundação Carlos Chagas (2004), que demonstra a participação de mulheres no trabalho formal ocorria de forma restrita, entre 1985 e 2002, apresenta-se um panorama crescente, de forma lenta, mas persistente. Entre 1992 e 2002, as empresas informaram a abertura de 2.968 .779 novos postos de trabalho para os homens, e de 3.423.024 para as mulheres. Completando essa análise, Lavinas (1999) demonstra que, desde 1980, a taxa anual de emprego das mulheres mostra-se mais elevada que a masculina, levando a um forte aumento do sexo feminino entre os ocupados. A absorção da mão-de-obra feminina tem sido, portanto, superior à masculina em todas as fases recentes da economia brasileira.

Com esse demonstrativo promissor, aparece além do crescimento sustentado da taxa de atividade feminina, outra tendência interessante que diz respeito ao melhor desempenho das mulheres na disputa por postos de trabalho. A importância do desempenho está focada na competência que permite concentrar a atenção à pessoa, mais do que sobre o posto de trabalho, possibilitando, assim, associar as qualidades requeridas para o cargo com as formas de cooperação com a equipe de trabalho (Lavinas, 1999).

A adaptação das mulheres ao ingressarem em postos de trabalho predominantemente masculinos melhora, conforme Hirata (2004) descreve em suas pesquisas, a partir do momento em que são retirados os obstáculos como: preconceitos, banalização do trabalho feminino e discriminação no ambiente de trabalho.

Outro fator decisivo na participação das mulheres no mercado formal de trabalho é o avanço tecnológico, onde a execução na operação e o controle de equipamentos industriais, em sua maioria, eram manuais e exigiam a força física. Essas atividades destinavam-se aos homens no passado. Com a automatização da maioria dos equipamentos, as exigências na operação desses deixam de evidenciar a força física como elemento fundamental na execução das tarefas (Fonseca, 2000). Embora a Petrobrás se constitua uma empresa com funções e cargos predominantemente masculinos, o investimento no avanço tecnológico é evidente, sendo um elemento importante na inserção das mulheres na área industrial.

Artigos científicos referentes ao trabalho da mulher revelam que geralmente as mulheres exercem a dupla jornada de trabalho, qualificando-a como as tarefas exercidas além do trabalho remunerado (Bruschini, 1998; Sebastiani, 2002 \& Hirata, 2004). A literatura tem sido farta em assinalar e vale a pena repetir, para essa análise, de que culturalmente as tarefas domésticas eram destinadas às mulheres, bem como o cuidado dos filhos. Esses fatores poderiam fazer com que a mulher optasse por não se inserir no mercado de trabalho, quando, por exemplo, a remuneração não compensasse os gastos praticados no âmbito doméstico. Esse estereótipo de que cabem às mulheres os cuidados com a casa e a família não deixou de existir e sim acarretou uma dupla cobrança, agora à sua responsabilidade com a família juntaram-se as responsabilidades profissionais (Pacheco, 2001).

Percebe-se o esforço dos sujeitos da pesquisa em compatibilizar trabalho em turno e família, o que não é tarefa fácil, mas possível de se elaborar estratégias que amenizem essas situações, como o fazem. Na dialética entre trabalho e momentos familiares encontram-se os sujeitos dessa pesquisa, ao mesmo tempo em que estão mergulhados na busca incansável de ter benefícios financeiros, sentem uma lacuna em participar coletivamente nas atividades familiares.

Diferenciando do que se encontra nas pesquisas, as mulheres que trabalham na Petrobrás buscam outras atividades remuneradas ou não, exercendo assim uma "tripla jornada" de trabalho, se assim poderia ser chamada. Ao mesmo tempo em que exercem suas atividades profissionais de operadoras, também auxiliam na organização no âmbito doméstico, orientando ou até mesmo executando algumas atividades e, ainda, preenchem seu tempo chamado de folga (espaços de seis dias 
que intercala a cada sénie de turno) com outras atividades. Essas atividades geralmente se referem à abertura do próprio negócio, atividades em outras empresas ou prestação de serviços gratuito na comunidade.

As mulheres relatam que no início de suas atividades havia tentativas, por parte dos homens, de poupá-las da execução de suas atribuições demonstrando tentar protegê-las das atividades laborais, consideradas por eles "pesadas", por exigirem esforço físico. Elas por sua vez alegavam aos homens que seria possível o desempenho das suas tarefas e, quando necessitassem de ajuda, pediriam a eles.

Rogério utiliza a expressão "bibelozinho" para representar as mulheres fragilizadas, afirmando que tentava poupá-las de suas atribuições uma vez que, mesmo oferecendo ajuda elas se recusam, alegando que aquela função pertence a elas.

Poupava, era um bibelozinho, (...) é uma proteção, e mais como eu te falei aquele cuidado não deixar fazer determinadas manobras, poupava mais as mulheres. Hoje não existe tanto isso. Hoje, mulher para nós é homem [risos]. Uma coisa interessante, que nem no caso (...) às vezes se a gente se oferece para ajudar, elas não a ceitam, elas são birrenta tudo: "não você tem que fazer força", "não eu faço", "não preciso". E antes não, antes a gente cuidava mais né: "fique aí deixe que eu vou lá fazer" e tal [Rogério].

Percebeu-se também algumas idéias explicitadas pelos homens, denunciando certas concepções de gênero ainda vigentes no imaginário social como: "mulher faz mais café", "são mais minuciosas" e "têm uma sensibilidade maior".

\section{Considerações Finais}

Compõe-se um cenário no século XXI, em que as funções não seriam pautadas em diferenças entre os sexos feminino e masculino e sim em competências e habilidades no desempenho no trabalho. Os impactos da economia brasileira constituíram e construíram processos que mobilizaram o avanço do trabalho feminino, onde 0 interesse possibilitou melhorar as condições socioeconômicas das famílias.

Lugares proibidos para mulheres, comportamentos aceitáveis socialmente, mãe protetora do lar, mulher direita não trabalha, essas frases estruturaram adjetivos reducionistas no sentido de não considerarem as mulheres parte do sistema produtivo no trabalho (Perrot, 1998). Assim, a participação da mulher na esfera produtiva social condiciona, de um lado, apreensão do significado daquela participação, reproduzindo a posição subalterna da mulher. De outro, apesar da manutenção desta posição, o caráter coletivo da nova condição de trabalhadora, partilhada num estreito e contínuo convívio, numa permanente troca de experiências, queixas, aspirações, satisfações, considerações sobre problemas comuns, constitui-se um espaço de reflexão e de possibilidades de ação e organização nos limites estreitos do reino doméstico.

As fronteiras da igualdade e desigualdade rodearam as mulheres em sua trajetória ao assumirem cargos predominantemente masculinos. Esse cenário de avanço em ocupações antes inacessíveis, a taxa de participação das mulheres no Brasil é de $55 \%$, superior à média latino-americana, mas ainda inferior aos níveis de muitos países desenvolvidos, como mostra o primeiro relatório da OIT - Organização Internacional do Trabalho (2003).

Embora essas transformações ocorram lentamente, este espaço vem sendo construído, permitindo formulações de reivindicações específicas das mulheres, numa demonstração de que a condição permanente e a problemática gerada pela nova condição da mulher na sociedade passam a requerer soluções também permanentes.

O lugar que ocupam as mulheres no trabalho na Petrobrás abrange posicionamentos competitivos, sendo igualitários o salário, a jornada de trabalho, os benefícios, enfim, no que tange aos procedimentos a igualdade impera. Ultrapassando as fronteiras do passado destacam-se essas mulheres (sujeitos da pesquisa) na inserção no mercado de trabalho rumo ao século XXI, onde as transformações de oportunidades de trabalho crescem no País.

Evidencia-se, também, que os homens fazem referências a respeito do cargo predominantemente masculino, partindo da concordância da participação feminina em locais e cargos considerados de domínio dos homens. Portanto, na empresa pesquisada observou-se a aceitabilidade das mulheres em postos de trabalho tradicionalmente masculinos, mesmo observando algumas diferenciações nas relações de gênero, especial- 
mente entre os homens há mais tempo na empresa, que mantêm a idéia de que não se trata de local de trabalho adequado para as mulheres.

Com todas essas mudanças, uma nova roupagem se anuncia nas organizações, a Petrobrás e o grupo pesquisado representam as transformações históricas que a literatura aponta: ingresso em atividades predominantemente masculinas, exercício dos direitos à maternidade, salários e benefícios equiparados.

Destacam também que os avanços tecnológicos contribuem como fator facilitador para a igualdade de desempenho entre homens e mulheres, pois minimizam a necessidade da força física. Aparece como vilão do trabalho de revezamento o turno, responsável pelo afastamento da família e do convívio social regular.

Esse grupo pesquisado evidencia o esforço mútuo em concretizar a pareceria entre homens e mulheres em ocupações que perduraram sendo de domínio masculino, sendo que as mulheres inserem-se no contexto da igualdade de oportunidades profissionais. Há que se reconhecer, entretanto, a inconstância das relações de poder a influenciar a articulação das relações de gênero, o que leva a inferir que o futuro depende da capacidade e da possibilidade que homens e mulheres terão para defenderem e negociarem seus interesses, construindo relações na busca da criação de um espaço, de um "saber conviver", a partir de ambigüidades, inerentes à realidade em que vivem (Campelle, 2001).

\section{Referências}

Amaral, C. C. G. (1999). Economia doméstica e as discussões sobre gênero. Revista Múltipla, 4(6), 111-116.

Bruschini, C. (1994). O trabalho da mulher brasileira nas décadas recentes. REF - Revista de Estudos Feministas, número especial, 175-199.

Bruschini, C. (1995). Mulher e trabalho: uma década da mulher. São Paulo: Nobel; Conselho Estadual da Condição Feminina.

Bruschini, C., \& Rosemberg, F. (1982). Trabalhadoras do Brasil. São Paulo: Brasiliense.
Bruschini, C. (1998). Trabalho feminino no Brasil: novas conquistas ou persistência da discriminação? In Meeting Latim American Studies Association, Eco 19. Chicago, Illinois - USA: Eco 19.

Camppelle, M. C. A, Melo, M. C. O. L., \& Brito, M. J. M. (2001). As representações sociais das relações de gênero na educação superior: a inserção do feminino no universo masculino [CD]. In Anais da ENAMPAD - Encontro da Associação Nacional de Pós-graduação em Administração, Florianópolis. $1 \mathrm{CD}$

Delgado, D. G., Cappellin P., \& Soares V. (2000). Mulher e Trabalho. São Paulo: Bom tempo.

Organização Internacional do trabalho. (2003). Genebra. Relatório global sobre discriminação no trabalho.

Sebastiani, R. V. (2002). Gênero e desigualdade salarial. Dissertação de mestrado, UFRGS, Porto Alegre.

Fonseca, T. M. G. (2000). Gênero, subjetividade e trabalho. Petrópolis: Vozes.

Hirata, H. (2004). Nova divisão sex ual do trabalho? Um olhar voltado para a empresa e a sociedade. São Paulo: Bom tempo.

Pacheco, A. L. (2001). Trabalho e família sob o olhar feminino. Psico-Usf., 6(2).

Perrot, M. (1998). Mulheres públicas. São Paulo: UNESP.

Rocha, Maria Izabel Baltar da. (2000). Trabalho e gênero: mudanças, permanências e desafios. São Paulo: Editora 34

Scott, J. (1995). Gênero: uma categoria útil de analise histórica. Educação e Realidade, 20(2), 71100.

Instituto Brasileiro de Geografia e Estatística. Pesquisa Nacional por Amostra de Domicilio PNAD. Recuperado em 20 jul.de 2005: www.ibge.gov.br.

Recebido em/received in: 23/03/2006 Aprovado em/approved in: 03/04/2006 